\title{
Isolation and characterization of microsatellite markers in Ruditapes philippinarum
}

\author{
Z.B. Li, Y.F. Ning, J.B. Shangguan, B.B. Li, X.Q. Mao, Y.S. Huang and \\ Y. Yuan \\ Fujian Provincial Key Laboratory of Marine Fishery Resources and \\ Eco-Environment, Xiamen, China \\ Corresponding author: Z.B. Li \\ E-mail: lizhongbao@jmu.edu.cn \\ Genet. Mol. Res. 15 (2): gmr. 15027742 \\ Received September 29, 2015 \\ Accepted February 12, 2016 \\ Published May 23, 2016 \\ DOI http://dx.doi.org/10.4238/gmr.15027742
}

\begin{abstract}
Ruditapes philippinarum is considered a commercially valuable species, which is commonly found in tidal flats along West Pacific coasts. In China, it is mainly distributed in the southeast sea. In this study, 16 novel microsatellite loci from the $R$. philippinarum genome were developed, using the protocol of fast isolation by amplified fragment length polymorphism of sequence containing repeats. Thirty-two wild-caught individuals were used to evaluate the degree of polymorphism of these markers. Our results show that there were 10 polymorphic loci and 6 monomorphic loci. The number of alleles per locus and the polymorphism information content ranged from 2 to 6 and from 0.199 to 0.751 , respectively. The observed and expected heterozygosities varied from 0.1333 to 0.6207 and 0.1603 to 0.7412 , respectively. Of all loci, only one locus was found to deviate significantly from Hardy-Weinberg equilibrium after Bonferroni correction. The loci identified here will provide useful information for future population genetic studies of $R$. philippinarum.
\end{abstract}

Key words: Ruditapes philippinarum; Microsatellites; Genetic markers; FIASCO 


\section{INTRODUCTION}

Ruditapes philippinarum is considered a commercially valuable species, widely distributed on tidal flats in the West Pacific coasts from Russia to the Philippines (Allam et al., 2000; Mura et al., 2011). In China, it is mainly distributed in the north and south coastal waters (Yan et al., 2006). It belongs to the family Veneridae, and because of its characteristics of rapid growth, short breeding cycle, and strong adaptability to a wide salt and temperature ranges, it is highly suitable for artificial, high-density breeding of shellfish (Park and Choi, 2001). Recently, it has become one of China's four major farmed shellfishes. Being among the most economically important mollusks, its 2009 annual yield was 3 million tons, accounting for $30 \%$ of shellfish aquaculture production and close to $20 \%$ of the mariculture production (Chong and Wang, 2001). The Chinese market has a huge potential, with the improvement of people's living standards and short supply in both domestic and foreign markets. Due to lack of attention to the natural resource conservation of $R$. philippinarum, its natural production has been declining every year. Therefore, there is currently a serious shortage of seedlings, causing a "bottleneck" that restricts the development of $R$. philippinarum breeding (Kang et al., 2006). There is therefore an urgent need to establish proper molecular genetic marker techniques that can be used to study its genetic structure, test the level of genetic variation, and aid in establishing molecular marker assisted breeding and genetic improvement.

Microsatellite DNA refers to tandem-repeated nucleotides in the DNA sequence, which are also known as simple sequence repeats (SSR) or short tandem repeats (STR) (Cao et al., 2012). Compared with other molecular markers, microsatellite markers are non-coding, highly polymorphic, and have high information content. Microsatellites also exhibit high repeatability, co-dominant inheritance, and are currently widely used in studies of population genetics, population differentiation, linkage analysis, and evolution ( $\mathrm{Li}$ et al., 2014; Ning et al., 2015). To date, population genetic studies of $R$. philippinarum have mainly been based on RAPD, EST SSR, SRAP, and mitochondrial COI genetic markers, etc. However, there are no studies of the magnetic bead enrichment method that is currently used to develop $R$. philippinarum microsatellite markers. Using this method, this line of research aims at performing clam population genetic analyses and developing and providing technical support to an assisted breeding and germplasm resource protection community. In the present study, a novel marker suite of $16 R$. philippinarum loci was developed. This may be useful for future population genetic studies and for the protection of the species resources.

\section{MATERIAL AND METHODS}

\section{DNA extraction and microsatellite library construction}

We report 16 R. philippinarum microsatellite markers identified using the fast isolation by amplified fragment length polymorphism of sequences containing repeats (FIASCO) protocol (Zane et al., 2002). Firstly, 32 wild, healthy adult $R$. philippinarum individuals were collected from Xiamen, China. Genomic DNA was extracted from adductor muscle tissue, using the Genomic DNA Extraction kit (Tiangen, Beijing, China) following the manufacturer instructions. Enriched DNA was estimated by ultraviolet spectrophotometer analysis and electrophoresis on a $1 \%$ agarose gel. The obtained DNA was diluted to $100 \mathrm{ng} / \mu \mathrm{L}$, followed by digestion with $10 \mathrm{U}$ restriction enzyme FastDigest Tru1I in a $25 \mu \mathrm{L}$ volume, incubated 
for $10 \mathrm{~min}$ at $65^{\circ} \mathrm{C}$. The digested fragments, ranging from 500 to $1200 \mathrm{bp}$, were purified and ligated overnight at $22^{\circ} \mathrm{C}$ to $\mathrm{MseI}$ adapter 1 (5'-ACGATGAGTCCTGAG-3')/MseI adapter 2 (5'-TACTCAGGACTCAT-3') by T4 DNA ligase (Fermentas, Vilnius, Lithuania). The digestion-ligation mixture was subsequently denatured and hybridized to the biotin-labeled oligo-nucleotide probes $(\mathrm{CT})_{15}$ and $(\mathrm{GT})_{15}$. Fragments containing microsatellite repeats were captured with Streptavidin-coated Magnetic Sphere Particles (Promega, Madison, WI, USA), and non-annealed DNA was washed away. The recovered products were amplified using $\mathrm{MseI}$ adapter 1, and the polymerase chain reaction (PCR) products were subsequently purified by removing extra dNTPs and adaptors. Finally, the purified products were ligated to the pMD19-T vector (TaKaRa, Shiga, Japan) and then transformed into Escherichia coli (Invitrogen, Carlsbad, CA, USA) for further selection on ampicillin plates.

\section{Gaining SSR fragments and designing specific primers}

Positive clones were amplified via colony-PCR with universal M13 primers. DNA fragments $>500 \mathrm{bp}$ were sequenced by the Invitrogen Company (Shanghai, China). Specific primers with SSR sequences were designed using Primer Premier v. 5.0 (Singh et al., 1998). The amplification conditions of all primers were selected through optimization in an Eppendorf Mastercycler Gradient System (Eppendorf, Hamburg, Germany).

\section{Polymorphism validation}

Primers that amplified successfully were validated in the genomic DNA of the 32 wild-caught $R$. philippinarum individuals. The PCR amplification conditions consisted of a $10-\mu \mathrm{L}$ volume containing $50 \mathrm{ng}$ genomic DNA, 10X Taq buffer, $2 \mathrm{mM} \mathrm{MgCl}, 0.4 \mu \mathrm{M}$ each primer, $0.2 \mathrm{mM}$ each dNTP, and 0.25U Taq DNA Polymerase (Fermentas). The PCR was carried out under the following conditions: pre-denature at $94^{\circ} \mathrm{C}$ for $5 \mathrm{~min}$, followed by 37 cycles of denaturing at $94^{\circ} \mathrm{C}$ for $40 \mathrm{~s}$, annealing at optimal temperature (Table 1) for $40 \mathrm{~s}$, and $72^{\circ} \mathrm{C}$ for $1 \mathrm{~min}$, with a final 10 min elongation step at $72^{\circ} \mathrm{C}$. The PCR products were electrophoresed on 6\% denaturing polyacrylamide gels in a Sequi-Gen Sequencing Cell (BioRad, Hercules, CA, USA) and were then visualized by silver staining.

\section{Statistical analysis and interpretation}

The data matrix was analyzed by the statistical software POPGEN 32 (v. 1.32) (Yeh et al., 2000) and CERVUS 3.0 (v. 3.0) (Yeh et al., 2000). The number of alleles per locus and the polymorphic information content (PIC) were calculated using POPGEN 32 (v. 1.32), while the observed and expected heterozygosities were calculated by CERVUS 3.0 (v. 2.2.3). Deviations from Hardy-Weinberg equilibrium and genotypic linkage disequilibrium were tested using POPGENE 32.

\section{RESULTS}

\section{Cloning and sequencing results}

A total of 180 positive clones were amplified via colony-PCR with universal M13 
primers. Of these, 140 microsatellite sequences of $>500$ bp were successfully obtained. Most of these contained two and four base pair repeats, but a few also contained repeats consisting of three to more than five bases. There were no impure peaks, sets of peaks, or wave peaks appearing in the sequencing results.

Table 1. Statistical information of 10 polymorphic microsatellite loci found in 32 individuals of Ruditapes philippinarum.

\begin{tabular}{|c|c|c|c|c|c|c|c|c|c|}
\hline GenBank accession No. & Locus ID & Primer sequences $\left(5^{\prime}-3^{\prime}\right)$ & Repeat motif & $\mathrm{Ta}\left({ }^{\circ} \mathrm{C}\right)$ & $N_{\mathrm{A}}$ & PIC & $H_{\mathrm{O}}$ & $H_{\mathrm{E}}$ & Allele size (bp) \\
\hline KR704619 & F1 & $\begin{array}{l}\text { F: AAGGAAAGACGGCTTCG } \\
\text { R: GTGATTTGACCACAGGGAC }\end{array}$ & $(\mathrm{CT})_{14}$ & 53 & 4 & 0.494 & 0.2105 & 0.2845 & $183-210$ \\
\hline KR704620 & F2 & $\begin{array}{l}\text { F: ATTCCATTAGCACCTCT } \\
\text { R: CACACACACCCACACA }\end{array}$ & (TGCG)5 & 43 & 5 & 0.333 & 0.2759 & 0.3091 & $135-155$ \\
\hline KR704621 & F3 & $\begin{array}{l}\text { F: ATATCTGCCTGCTGGTAA } \\
\text { R: TCGGTCAAGCCTTTCA }\end{array}$ & $(\text { GTCG })_{4}$ & 49 & 4 & 0.438 & 0.6207 & 0.5136 & $148-174$ \\
\hline KR704622 & F4 & $\begin{array}{l}\text { F: GCTTTCAGCCACCATCC } \\
\text { R: AGACATTCCAGGTAGTCCAAC }\end{array}$ & $(\mathrm{GAT})_{3}$ & 53 & 6 & 0.751 & 0.4400 & 0.7412 & $200-231$ \\
\hline KR704623 & F5 & $\begin{array}{l}\text { F: CTAATGACTGACTTTGCTCT } \\
\text { R: TCTGTAGTCCCCAACCC }\end{array}$ & $(\mathrm{GA})_{35}(\mathrm{GA})_{5}$ & 48 & 2 & 0.324 & 0.3000 & 0.4130 & $200-207$ \\
\hline KR704624 & F6* & $\begin{array}{l}\text { F: GAACTTGCGACCCAGAG } \\
\text { R: AACACCCCAACGGACTA }\end{array}$ & $(\text { GTT })_{3}$ & 50 & 3 & 0.199 & 0.1724 & 0.1603 & $216-240$ \\
\hline KR704625 & F7 & $\begin{array}{l}\text { F: TTTCATCCACCATCCTCC } \\
\text { R: CACAAACATAGAAGTCCCAGT }\end{array}$ & $(\mathrm{GAT})_{3}$ & 52 & 4 & 0.566 & 0.4643 & 0.5981 & $275-297$ \\
\hline KR704626 & F8 & $\begin{array}{l}\text { F: AGACGGGAACATCACCAT } \\
\text { R: AAACCGCACCTGACACC }\end{array}$ & $(\mathrm{GACAAG})_{3}$ & 53 & 5 & 0.665 & 0.2800 & 0.6408 & $220-243$ \\
\hline KR704627 & F9 & $\begin{array}{l}\text { F: TTCCTCCCTCGCTTCAC } \\
\text { R: AGATGGATGGCACTGGTT }\end{array}$ & $(\mathrm{CA})_{5}$ & 53 & 3 & 0.403 & 0.5357 & 0.3994 & $199-218$ \\
\hline KR704628 & F10 & $\begin{array}{l}\text { F: ACCGCACCTGACACTCT } \\
\text { R: ACGGGAACATCACCATC }\end{array}$ & $(\mathrm{CTTGTC})_{3}$ & 50 & 5 & 0.206 & 0.1333 & 0.2181 & $230-254$ \\
\hline
\end{tabular}

$\mathrm{Ta}=$ annealing temperature; $N_{\mathrm{A}}=$ number of polymorphic alleles per locus; $\mathrm{PIC}=$ polymorphism information content; $H_{\mathrm{O}}=$ observed heterozygosity; $H_{\mathrm{E}}=$ expected heterozygosity; $*$ high significant deviations $(\mathrm{P}<0.001)$ of locus from Hardy-Weinberg equilibrium after Bonferroni correction $(\mathrm{k}=10)$.

\section{Polymorphic analysis}

We designed 45 pairs of specific primers. The optimized PCR products were visualized on $6 \%$ denaturing polyacrylamide gels, e.g., the polymorphic locus F2 shown in Figure 1. We were able to successfully amplify 16 novel microsatellite markers, including ten polymorphic microsatellite loci (Table 1) and six monomorphism loci (Table 2).

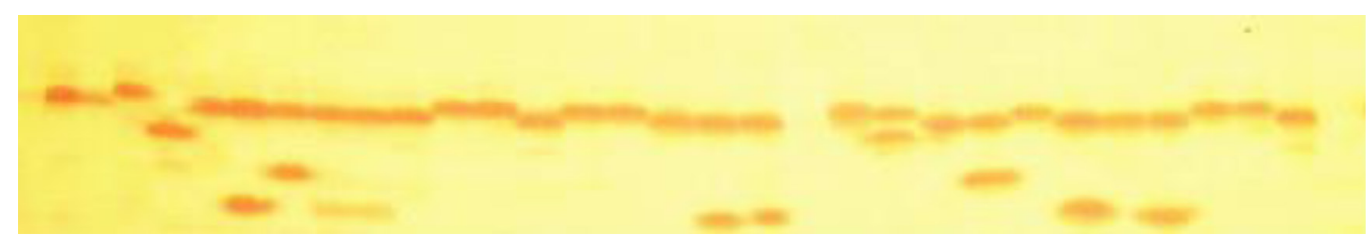

Figure 1. Electrophoretogram of the amplification of the F2 locus.

The number of alleles ranged from two to six, whereas the PIC ranged from 0.199 to 0.751 . The levels of expected and observed heterozygosities varied from 0.1333 to 0.6207 and 0.1603 to 0.7412 , respectively. Even after sequential Bonferroni correction $(\mathrm{P}<0.0005)$, most loci were in Hardy-Weinberg equilibrium, except for locus F6. This may be attributed to the limited number of samples tested. 


\begin{tabular}{|c|c|c|c|c|c|c|c|c|c|}
\hline GenBank accession No. & Locus ID & Primer sequences $\left(5^{\prime}-3^{\prime}\right)$ & Repeat motif & $\mathrm{Ta}\left({ }^{\circ} \mathrm{C}\right)$ & $N_{\mathrm{A}}$ & PIC & $H_{\mathrm{O}}$ & $H_{\mathrm{E}}$ & Allele size (bp) \\
\hline KR704629 & F11 & $\begin{array}{l}\text { F: TTCCATTAGTACCTCTATAAAA } \\
\text { R: GAAACGTCAAGTCATCTTC }\end{array}$ & $(\mathrm{AG})_{6} \mathrm{~N}(\mathrm{GT})_{22}$ & 46 & - & - & - & - & 315 \\
\hline KR704630 & F12 & $\begin{array}{l}\text { F: ATCACCGACTTGAGCAG } \\
\text { R: TAAAGCCTCCCGTAAAT }\end{array}$ & $(\mathrm{CA})_{29} \mathrm{~N}(\mathrm{CT})_{24} \mathrm{~N}(\mathrm{TC})_{12}$ & 47 & - & - & - & - & 268 \\
\hline KR704631 & F13 & $\begin{array}{l}\text { F: TGTTCCTTTGTTTGTTCGTT } \\
\text { R: CCTGTAGGTCACCGTTGC }\end{array}$ & $(\mathrm{GT})_{20}(\mathrm{CGTG})_{3}(\mathrm{GT})_{25}$ & 53 & - & - & - & - & 192 \\
\hline KR704632 & F14 & $\begin{array}{l}\text { F: GAAACCGCACCTGACACC } \\
\text { R: CAACAATCTCAAGGAGGAAAC }\end{array}$ & $(\text { CTTGTC })_{3}$ & 55 & - & - & - & - & 314 \\
\hline KR704633 & F15 & $\begin{array}{l}\text { F: ATCCCTACCCCGAAACA } \\
\text { R: TCCGATTATTGTCCTATCACTT }\end{array}$ & $(\mathrm{AT})_{5}$ & 53 & - & - & - & - & 274 \\
\hline KR704634 & F16 & $\begin{array}{l}\text { F: TTACCCCTCGTTTCTGC } \\
\text { R: CCAAATCTTTTATGCTGA }\end{array}$ & $(\mathrm{TCTG})_{4}$ & 49 & - & - & - & - & 330 \\
\hline
\end{tabular}

\section{DISCUSSION}

Despite the well-known importance of $R$. philippinarum, its genetic information has been studied relatively little. In general, this research field currently mostly uses SSR/SNP markers to study genetic diversity. However, SSR markers are a more appropriate choice when dealing with rare species and requires substantial funding. In this study, we used the FIASCO protocol to identify 10 polymorphic loci and six monomorphic loci. Xing et al. (2014) used 10 published primers to study cultured and wild populations of $R$. philippinarum in China. Therefore, the results of this study can be used as candidate gene loci to study population genetics. We developed a relatively small number of loci, due to the limitation in sample collection from different sites. To investigate genetic diversity of two Korean populations, Kim et al. (2014) developed 10 polymorphic loci from expressed sequence tag-derived microsatellite markers, using next-generation sequencing. Different methods used to develop SSR loci for the same species differ in efficiency. In this study, we had a $77.78 \%$ positive rate of cloning, which greatly exceeded the $0.52 \%$ achieved in Kim et al. (2014). This phenomenon could be due to the construction of an aimed SSR gene library. Following the library construction, 10 polymorphic loci out of 45 loci $(22.22 \%)$ were screened that contained two to six different nucleotide repeat motifs. This rate of polymorphism is slightly higher than the $16.1 \%$ found in the same species (Kim et al., 2014). In our study, six monomorphic loci were also identified. These could be the result of conserved properties of the loci or low genetic diversity, but in the future, these too may play an important role in genetic studies of $R$. philippinarum.

This study was limited by the number of populations and the methods used for testing for polymorphism. Although the series of procedures used for developing and screening the SSR loci were complicated, the efficiency was satisfactory. In conclusion, these novel microsatellite markers isolated for $R$. philippinarum, will increase and supplement the genetic information background for this species. These loci will be useful for studies of genetic diversity, population structure, the construction of genetic map, and conservation strategy design.

\section{Conflicts of interest}

The authors declare no conflict of interest. 


\section{ACKNOWLEDGMENTS}

Research supported by the Natural Science Foundation of Fujian Province (\#2014J01133), the National Natural Science Foundation of China (\#31272668), the Foundation for Innovative Research Team of Jimei University, China (\#2010A004), and the Program for New Century Excellent Talents in Fujian Province University [(\#2006)35].

\section{REFERENCES}

Allam B, Paillard C and Auffret M (2000). Alterations in hemolymph and extrapallial fluid parameters in the Manila clam, Ruditapes philippinarum, challenged with the pathogen Vibrio tapetis. J. Invertebr. Pathol. 76: 63-69. http://dx.doi. org/10.1006/jipa.2000.4940

Cao YY, Li ZB, Li QH, Chen XJ, et al. (2012). Development and characterization of microsatellite loci for Fenneropenaeus penicillatus Alcock. Afr. J. Biotechnol. 11: 10831-10833.

Chong K and Wang WX (2001). Comparative studies on the biokinetics of Cd, Cr, and Zn in the green mussel Perna viridis and the Manila clam Ruditapes philippinarum. Environ. Pollut. 115: 107-121. http://dx.doi.org/10.1016/ $\underline{\mathrm{S} 0269-7491(01) 00087-2}$

Kang YS, Kim YM, Park KI, Kim Cho S, et al. (2006). Analysis of EST and lectin expressions in hemocytes of Manila clams (Ruditapes philippinarum) (Bivalvia: Mollusca) infected with Perkinsus olseni. Dev. Comp. Immunol. 30: 1119-1131. http://dx.doi.org/10.1016/j.dci.2006.03.005

Kim EM, An HS, Kang JH, An CM, et al. (2014). New polymorphic microsatellite markers for the Korean manila clam (Ruditapes philippinarum) and their application to wild populations. Genet. Mol. Res. 13: 8163-8173. http://dx.doi. org/10.4238/2014.October.7.11

Li QH, Li ZB, Dai G, Cao YY, et al. (2014). Isolation and characterization of eleven microsatellite loci in the marbled rockfish, Sebastiscus marmoratus (Scorpaenidae). Conserv. Genet. Resour. 6: 53-55. http://dx.doi.org/10.1007/ $\underline{\text { s12686-013-0001-y }}$

Mura L, Cossu P, Lai T, Cannas A, et al. (2011). Survey of the genetic variability of populations of Ruditapes philippinarum from the Gulf of Olbia (N-E Sardinia) by microsatellites. Biol. Mar. Mediterr. 18: 266-267.

Ning YF, Li ZB, Li QH, Dai G, et al. (2015). Isolation and characterization of novel microsatellite markers for molecular genetic diversity in Siganus fuscescens. Genet. Mol. Res. 14: 89-92. http://dx.doi.org/10.4238/2015.January.15.11

Park KII and Choi KS (2001). Spatial distribution of the protozoan parasite Perkinsus sp. found in the Manila clams, Ruditapes philippinarum, in Korea. Aquaculture 203: 9-22. http://dx.doi.org/10.1016/S0044-8486(01)00619-6

Singh VK, Mangalam AK, Dwivedi S and Naik S (1998). Primer premier: program for design of degenerate primers from a protein sequence. Biotechniques 24: 318-319.

Xing K, Gao ML and Li HJ (2014). Genetic differentiation between natural and hatchery populations of Manila clam (Ruditapes philippinarum) based on microsatellite markers. Genet. Mol. Res. 13: 237-245. http://dx.doi. org/10.4238/2014.January.17.7

Yan XW, Zhang GF and Yang F (2006). Effects of diet, stocking density, and environmental factors on growth, survival, and metamorphosis of Manila clam Ruditapes philippinarum larvae. Aquaculture 253: 350-358. http://dx.doi. org/10.1016/j.aquaculture.2005.07.030

Yeh FC, Yang R, Boyle TJ, Ye Z, et al. (2000). PopGene32, Microsoft Windows-based freeware for population genetic analysis. Version 1.32, Molecular Biology and Biotechnology Centre University of Alberta, Alberta.

Zane L, Bargelloni L and Patarnello T (2002). Strategies for microsatellite isolation: a review. Mol. Ecol. 11: 1-16. http:// dx.doi.org/10.1046/j.0962-1083.2001.01418.x 